\title{
Competitive interactions, structure and properties in polymer/layered silicate nanocomposites
}

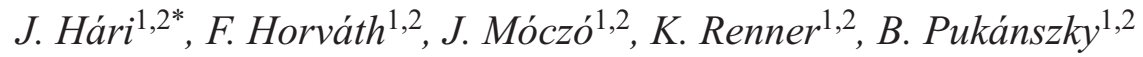 \\ ${ }^{1}$ Laboratory of Plastics and Rubber Technology, Department of Physical Chemistry and Materials Science, Budapest \\ University of Technology and Economics, H-1521 Budapest, P.O. Box 91, Hungary \\ ${ }^{2}$ Institute of Materials and Environmental Chemistry, Research Centre for Natural Sciences, Hungarian Academy of \\ Sciences, H-1519 Budapest, P.O. Box 286, Hungary
}

Received 17 November 2016; accepted in revised form 23 January 2017

\begin{abstract}
Thermoplastic polymer/layered silicate composites were prepared from the same organophilized montmorillonite (OMMT) and four different matrices, polypropylene (PP), the blend of PP and a maleated polymer (MAPP), poly(lactic acid) (PLA) and polyamide (PA) in order to study the effect of their chemical structure and interactions on composite structure and properties. The components were homogenized by extrusion and then specimens were injection molded, which were then characterized by a variety of methods. The results showed that competitive interactions among silicate layers and between the silicate and the polymer determine the extent of exfoliation, and structure. The morphology of the composites is complicated, exfoliation is never complete, besides individual silicate layers, the composite can contain a silicate network, stacks of silicate platelets and larger particles in various amounts. Several local deformation processes can take place around the structural entities as well as in the matrix. Fracture and debonding are the main particle related processes, while cavitation takes place in the polymer, at least in PA and PLA. The macroscopic properties of layered silicate composites are determined by the extent of exfoliation and interfacial adhesion that decreases upon organophilization. Increased reinforcement and improved composite properties can be achieved only by the proper control of all interactions prevailing in the composite.
\end{abstract}

Keywords: nanocomposites, interactions, local deformations, acoustic emission, volume strain

\section{Introduction}

Although the interest in polymer/layered silicate nanocomposites has ebbed somewhat recently, relatively intensive work is going on in the field and a large number of papers are published [1-14]. The decrease of interest is caused by the fact that the nano hype has not been justified and a breakthrough has not occurred in the application of such composites. Although the original idea of creating a large interface in the composite by the exfoliation of the silicate and thus achieving strong reinforcement at small filler content is still valid [15-18], the main problem is that a large extent of exfoliation and the control of nanocomposite structure could not be achieved practically at all. A way to reach the original goal of layered silicate nanocomposites is a more thorough study of competitive interactions prevailing among all components, the proper characterization of structure and the determination of the role of the various structural formations in the deformation, failure and properties of the composites.

Since complete exfoliation is rarely or practically never achieved, the structure of layered silicate composites is complex. The main techniques used for the characterization of such composites are transmission electron microscopy (TEM) and X-ray diffraction (XRD) $[5,15,16]$. The first is able to detect the presence of exfoliated, individual silicate layers, while

\footnotetext{
${ }^{*}$ Corresponding author, e-mail: jhari@mail.bme.hu (C) BME-PT
} 
the second gives information on the gallery structure of non-exfoliated silicate stacks (tactoids). Both techniques have drawbacks and the characterization of the structure of layered silicate composites must be supplemented with further methods. Because of its high resolution TEM does not supply information about larger structural entities, like larger stacks and especially particles. XRD is used to supply information on intercalation or exfoliation and the disappearance of the silicate reflection from the XRD pattern is falsely interpreted as a sign of complete exfoliation [19-23]. Usually subtle changes in gallery structure are not analyzed sufficiently thoroughly and reflection intensity indicating the amount of non-exfoliated silicates is not evaluated quantitatively practically at all [24]. Several studies clearly proved that the structure of layered silicate composites is complex [24-27]. Usually it contains individual layers and tactoids, but a silicate network may also form at larger extent of exfoliation and large non-exfoliated particles are also present in the composite practically always [24]. These latter usually are not detected, because they are not looked for; their presence must be checked by scanning electron microscopy (SEM). The various structural entities behave differently during the deformation of the composite and determine local processes as well as the final properties of the composites.

Another crucial question not treated according to its importance is related to the interactions prevailing in the composite. Usually organophilic silicate is used for the preparation of these composites [22, 28-30]. Organophilization, i.e. the modification of the surface by long aliphatic chains is falsely claimed to improve compatibility between the matrix polymer and the silicate [31, 32]. Layered silicates usually have very high energy surfaces thus the polymer adheres to them strongly. Organophilization decreases surface energy and thus also the strength of interaction between the polymer and the silicate [33]. The goal of organophilization is not to increase compatibility, but to decrease the strength of interactions among silicate layers, increase gallery distance and facilitate exfoliation, unfortunately on the expense of decreasing matrix/silicate interactions. It is clear, however, that competitive interactions determine the structure and properties of such composites which must be analyzed in order to understand their effect. The interactions among the silicate layers compete with those between the silicate and the polymer and both are modified by the type and amount of surfactant used for treatment.

Although an enormous number of papers have been published on layered silicate composites prepared from a wide variety of silicates and polymers up to now $[1-6,15,16]$, very few of them compare the influence of the same silicate on composite structure and properties in different polymers [34, 35]. Differences in the structure of the matrix polymer lead to dissimilar interactions and thus to different structure and properties. In view of the considerations presented above, the goal of this work was to compare interactions, structure and properties in thermoplastic polymer/layered silicate composites prepared with the same organophilic silicate, but with different matrix polymers. Special attention is paid to the analysis of structure and to the estimation of interactions, but structure-property correlations are also considered in the final section of the paper.

\section{Experimental}

\subsection{Materials}

The same organophilic silicate, Cloisite 20A (Rockwood Additives Ltd., USA), was used in all composites. Sodium montmorillonite is treated with distearyl-dimethyl-ammonium chloride to obtain the organophilized product (OMMT). The ion exchange capacity of the silicate is $92.6 \mathrm{meq} / 100 \mathrm{~g}$, it is coated with $37.8 \mathrm{wt} \%$ of the surfactant resulting in $106 \%$ surface coverage, if we calculate it from the theoretical specific surface area of the silicate $\left(750 \mathrm{~m}^{2} / \mathrm{g}\right)$ or $120 \%$ calculated from its ion exchange capacity. The layer distance of the silicate is $2.7 \mathrm{~nm}$ corresponding approximately to 6 aliphatic chains [33]. The average particle size of the filler is $13.9 \mu \mathrm{m}$ from the image analysis of SEM micrographs and $20.5 \mu \mathrm{m}$ determined by laser light scattering (Malvern Master Sizer 2000).

Composites were prepared from the OMMT in four matrices, a PP homopolymer, PLA and PA. The fourth matrix was also PP, but a functionalized polymer, maleated polypropylene (MAPP), was also added in $20 \mathrm{vol} \%$ (calculated for the silicate) in order to modify interactions. The most important characteristics of the polymers used are collected in Table $1.2000 \mathrm{ppm}$ Irganox 1010 and 2000 ppm Irgafos 168 stabilizers were added to PP based composites to prevent degradation during processing [36]. All composites contained the silicate at $0.5,1,1.5,2,3,5$ and 7 vol\%. Under silicate content we always understand the 
Table 1. The most important characteristics of the polymers used in the experiments

\begin{tabular}{|l|l|l|c|c|c|c|}
\hline \multicolumn{1}{|c|}{ Polymer } & \multicolumn{1}{|c|}{ Type } & \multicolumn{1}{|c|}{ Producer } & $\begin{array}{c}\boldsymbol{M}_{\mathbf{n}} \\
{[\mathbf{g} / \mathbf{m o l}]}\end{array}$ & $\boldsymbol{M}_{\mathbf{w}} / \boldsymbol{M}_{\mathbf{n}}$ & $\begin{array}{c}\text { MFI } \\
{[\mathbf{g} / \mathbf{1 0} \mathbf{m i n}]}\end{array}$ & $\begin{array}{c}\text { Density } \\
{\left[\mathbf{g} / \mathbf{c m}^{\mathbf{3}}\right]}\end{array}$ \\
\hline PP & Tipplen H649F & Mol, Hungary & 68900 & 4.4 & $2.77^{\mathrm{b}} \pm 0.03$ & 0.90 \\
\hline MAPP & Orevac CA & Arkema, France & 25000 & 8.6 & $125.2^{\mathrm{c}} \pm 2.4$ & 0.90 \\
\hline PLA & Ingeo 4032 D & Nature Works, USA & 88500 & 1.8 & $3.73^{\mathrm{c}} \pm 0.19$ & 1.24 \\
\hline PA & Domamid 27 & Domo Chem., Belgium & $39600^{\mathrm{a}}$ & - & $20.0^{\mathrm{b}} \pm 2.0$ & 1.14 \\
\hline
\end{tabular}

${ }^{\mathrm{a}} M_{\mathrm{v}}$, intrinsic viscosity, in conc. sulfuric acid, at $25^{\circ} \mathrm{C}, a=0.78, K=3.32 \cdot 10^{-2} \mathrm{~cm}^{3} / \mathrm{g},{ }^{\mathrm{b}} 230^{\circ} \mathrm{C} / 2.16 \mathrm{~kg},{ }^{\mathrm{c}} 190^{\circ} \mathrm{C} / 2.15 \mathrm{~kg}$

amount of OMMT and not the neat, non-treated mineral.

\subsection{Sample preparation}

PLA and PA were thoroughly dried before each processing step (homogenization, injection molding); PLA at $100^{\circ} \mathrm{C}, 300$ mbar vacuum for 12 hours, while PA at $80^{\circ} \mathrm{C}$ for 4 hours in an air-circulation oven. The PP, PP/MAPP and the PLA composites were prepared under similar conditions. The components were homogenized using a Brabender DSK 42/7 twinscrew compounder equipped with a filament die of $3 \mathrm{~mm}$ diameter at $30 \mathrm{rpm}$ screw speed and at the temperature profile of $180-190-200-210^{\circ} \mathrm{C}$ in the case of PP, while at $190-200-210-220^{\circ} \mathrm{C}$ in the case of PLA. The granules produced in the compounding step were injection molded into standard ISO $5271 \mathrm{~A}$ tensile bars using a Demag IntElect 550-30 machine. The temperature profile used was 40-180-190-200$210^{\circ} \mathrm{C}$ and die temperature $40^{\circ} \mathrm{C}$, holding pressure 600 bar and holding time $35 \mathrm{~s}$ in the case of PP, while 450 bar and $35 \mathrm{~s}$ in the case of PLA. PA composites were processed by using a Berstorff ZE 34 Basic twin screw extruder at 60-210-225-230-230 $230^{\circ} \mathrm{C}$ and $50 \mathrm{rpm}$, while injection molding was done using the same Demag machine as above with the temperature profile of $40-235-240-250-260^{\circ} \mathrm{C}$ at the injection rate of $50 \mathrm{~mm} / \mathrm{s}$. The temperature of the mold was $60^{\circ} \mathrm{C}$, while holding pressure and time were 350 bar and $20 \mathrm{~s}$, respectively.

\subsection{Characterization}

The morphology of the composites was characterized by various techniques. Transmission electron micrographs were taken from ultrathin sections prepared with a Leica EM FC6 apparatus by a Tecnai G2 Twin microscope (LB6, 200 kV). SEM micrographs were recorded using a Jeol JSM 6380 LA apparatus on fracture surfaces created by the cryogenic fracture of neat and deformed samples. XRD traces were recorded on the composites using a Phillips PW 1830/ PW 1050 equipment with $\mathrm{CuK} \alpha$ radiation at $40 \mathrm{kV}$ and $35 \mathrm{~mA}$ anode excitation. The possible formation of a silicate network was checked by rotational viscometry using a Paar Physica USD 200 apparatus at $280^{\circ} \mathrm{C}(\mathrm{PA}), 190^{\circ} \mathrm{C}$ (PP and PP/MAPP), $180^{\circ} \mathrm{C}$ (PLA) in oscillatory mode in the frequency range of $0.1-6001 / \mathrm{sec}$ on discs with $25 \mathrm{~mm}$ diameter and $0.5 \mathrm{~mm}$ thickness in the parallel plate arrangement. The amplitude of the deformation was $5 \%$, which was in the linear elastic region checked by an amplitude sweep.

Mechanical properties were characterized by tensile testing using an Instron 5566 apparatus. Tensile modulus was determined at $0.5 \mathrm{~mm} / \mathrm{min}$ cross-head speed and $115 \mathrm{~mm}$ gauge length, while other tensile characteristics were measured at $5 \mathrm{~mm} / \mathrm{min}$ speed. All tensile bars were conditioned in an atmosphere of $50 \%$ relative humidity $(\mathrm{RH})$ and $23^{\circ} \mathrm{C}$ for 2 days before testing. PLA specimens were stored for four weeks before testing to allow physical ageing to take place. Acoustic emission (AE) signals were recorded with a Sensophone AED 40/4 apparatus. A single A11 resonance detector with the resonance frequency of $150 \mathrm{kHz}$ was attached to the center of the specimen. Pre-amplification was $20 \mathrm{~dB}$ and the peak amplitude detected by the equipment is $108 \mathrm{~dB} \mu \mathrm{V}$. Reference voltage was $1 \mathrm{mV}$. The threshold level of detection was set to $20 \mathrm{~dB}$. Volume strain (VOLS) was determined by measuring also the change in one lateral dimension of the specimen by a strain transducer. The same dimensional changes were assumed to occur in both lateral directions. The measurements were carried out at $5 \mathrm{~mm} / \mathrm{min}$ cross-head speed. Five parallel measurements were done in all mechanical and micromechanical experiments.

Interactions were estimated quantitatively by various approaches. The reversible work of adhesion was calculated from surface tensions determined by inverse gas chromatography for the silicate [33] and by contact angle measurements for the polymers. The effective load bearing capacity of the silicate was estimated from the composition dependence of tensile yield stress by an appropriate model $[37,38]$. Debonding 
stress [39] and a quantity characterizing interfacial adhesion was also derived from the results of acoustic emission experiments [40].

\section{Results and discussion}

The results of the experiments are presented and discussed in several sections. The composition dependence of mechanical properties is compared first for the four matrices then structure and local deformation processes are analyzed next. A separate section is dedicated to interactions and then correlations between structure and properties are discussed in the last section together with relevance to practice.

\subsection{Properties}

One of the main advantages, if not the main advantage, of layered silicate nanocomposites is the assumed large reinforcement obtained with a small amount of filler. Reinforcement means the increase of stiffness or strength, or both. The absolute increase in stiffness is not very impressive in our composites, modulus increases from 1.29 to $1.31 \mathrm{GPa}$ upon the addition of $7 \mathrm{vol} \%$ silicate to PP, while it changes from 1.09 to $2.75 \mathrm{GPa}$ in PA. Stiffness as large as $10 \mathrm{GPa}$ can be achieved in PP reinforced with carbon fibers [41]. The results obtained show that the basic idea does not work and the goal of large reinforcement is not achieved in our case. However, we are interested more in interactions and relative changes and these are different across the four matrices used.

The relative modulus of the four composites is plotted against silicate content in Figure 1. Stiffness increases

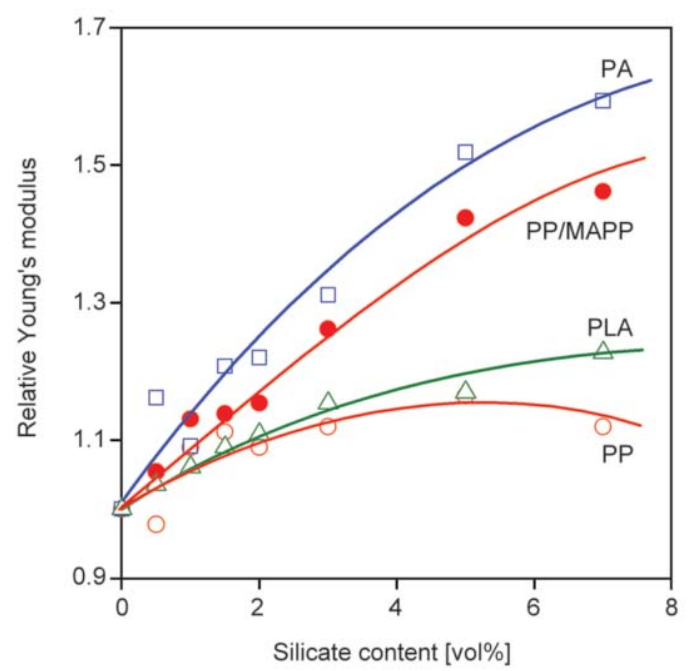

Figure 1. Relative modulus of polymer/silicate composites plotted as a function of OMMT content. Symbols:

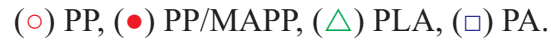

in all four cases, but in different extent. Although dissimilar relative increases were expected before the experiments, the order of the composites is somewhat surprising. The extent of reinforcement depends on the stiffness of the matrix and much less on homogeneity or interactions. The considerable increase of stiffness upon the introduction of the MAPP coupling agent and the small values obtained for PLA indicate dissimilar interfacial adhesion and/or different extent of exfoliation in the four cases.

Properties measured at larger deformations are influenced much more by these factors, i.e. structure and interactions, than stiffness. The relative yield stress of the four composites are plotted as a function of OMMT content in Figure 2. The relative order of the four composites remained the same as in the case of stiffness, but the differences are much larger. True reinforcement is achieved in PA, while yield stress decreases considerably for PLA and PP. Better adhesion in the PP/MAPP matrix resulted in a considerable increase of yield stress compared to neat PP. The reinforcing effect of any filler or reinforcement is difficult to judge from the absolute value of yield stress or even from the relative value related to the matrix polymer, since the effect of the effective matrix cross section must be considered [37, 38, 42] and matrix characteristics also influence reinforcement. Nevertheless, we can establish unambiguously that the different chemical structures of the matrix polymers studied result in dissimilar properties, presumably as an effect of different composite structures and interactions.

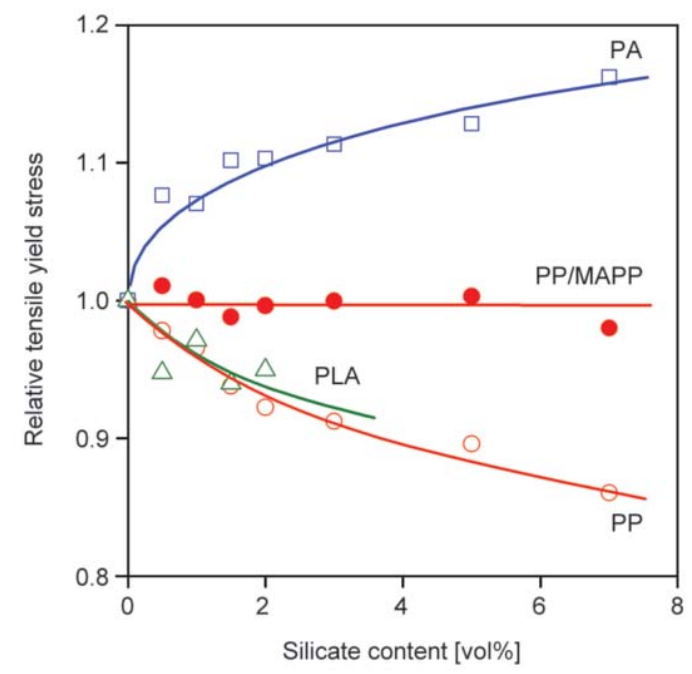

Figure 2. Effect of silicate content on the relative tensile yield stress of polymer/OMMT composites. Symbols are the same as in Figure 1 


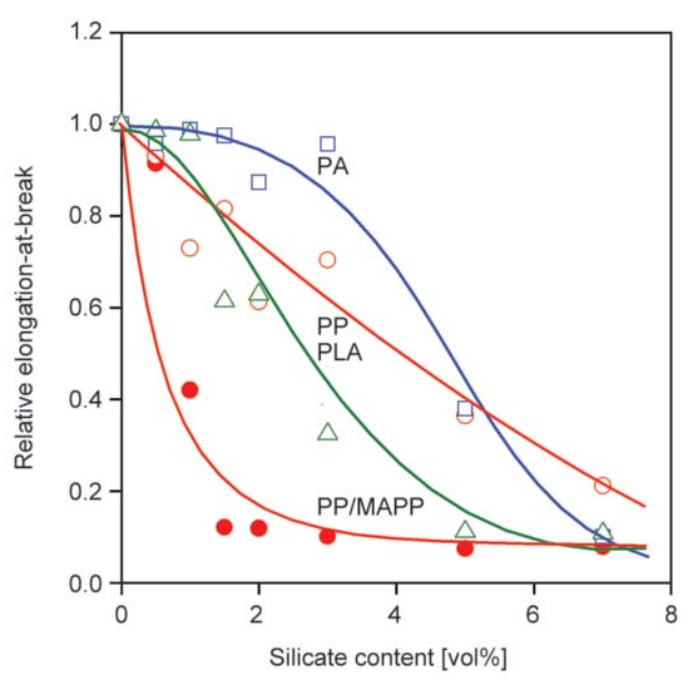

Figure 3. Dependence of the relative elongation-at-break of polymer/OMMT composites on silicate content. Symbols are the same as in Figure 1.

The deformability of the composites is presented in Figure 3 as a function of composition. Elongationat-break decreases with increasing silicate content in all cases, as expected. However, the actual values cover a wide range from very small to reasonable deformability. Improved interfacial adhesion results in very small deformability in the PP/MAPP composites and the small values obtained for PLA are more or less expected. The relatively large elongations measured in the PA composites are rather surprising especially in view of the fact that the largest reinforcement, both in stiffness and yield stress, was achieved in this polymer. Large stiffness usually leads to small deformability and fracture resistance. All mechanical properties measured indicate considerable differences among composites prepared with the four matrices probably because of dissimilar structure, interactions and possibly due to the influence of local deformation processes.

\subsection{Structure}

At the dawn of nanocomposite research all composites containing an organophilized layered silicate were claimed to have exfoliated structure [32, 43-45]. Since more detailed investigations showed that this is not true, structure changed to exfoliated/intercalated instead $[5,16,46]$, but the complexity of structure was still largely ignored. The ultimate proof of exfoliation was practically always a TEM micrograph showing individual silicate platelets. However, usually a few plates can be detected practically in every composite, thus it is better to look for other evidence as well. Above a certain extent of exfoliation

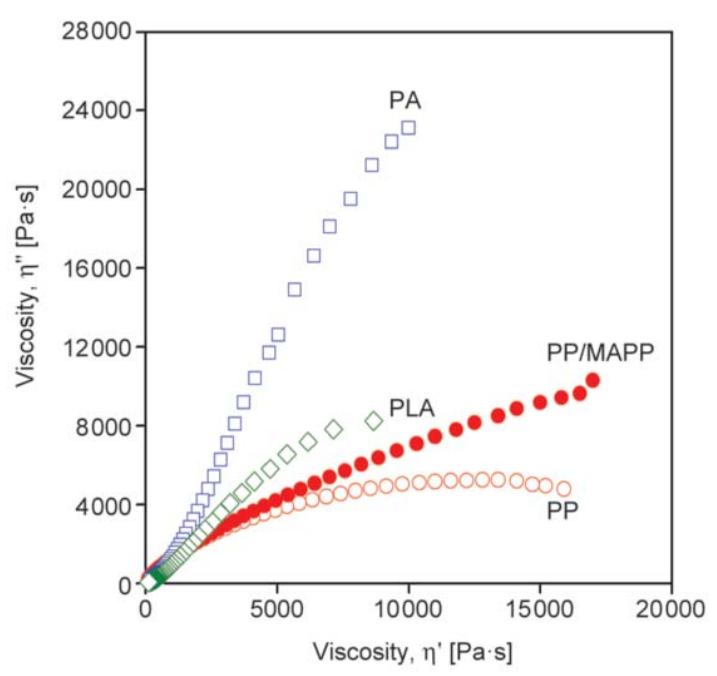

Figure 4. Cole-Cole plots ( $\eta^{\prime \prime}$ vs. $\eta^{\prime}$ ) of polymer/organophilized silicate composites. OMMT content:

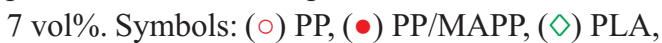
( $\square$ ) PA.

individual platelets form a silicate network, which can be detected quite well by melt rheology. ColeCole plots of the components of complex viscosity yield a regular or somewhat distorted arc, if the material possesses a single relaxation time, or a narrow distribution of relaxation times. The Cole-Cole plot of composites is also more or less a regular arc, when the second component is homogeneously dispersed in a matrix, but it strongly deviates from the arc if additional structural formations appear in the melt resulting in relaxation processes with two or more separate relaxation times [47-49]. The Cole-Cole plots of the composites are shown in Figure 4. The correlation corresponds to a perfect arc indeed for PP and also for PLA, i.e. for polymers in which reinforcement was the weakest. The addition of the MAPP coupling agent distorts the arc considerably and a completely different correlation is obtained for PA indicating dissimilar structure. The extent of deviation corresponds to the order observed in mechanical properties, on the one hand, while indicates the possible formation of a silicate network, i.e. considerable extent of exfoliation, on the other. Extensive exfoliation and the presence of silicate layers are demonstrated quite well by Figure 5 showing the TEM micrograph of a PA composite.

Complete exfoliation obviously cannot be expected in our composites, but tactoids, seen also in Figure 5, as well as larger particles must be also present. The XRD traces presented in Figure 6 clearly confirm this assumption and show the presence of ordered silicate structure. The first peak observed in the XRD 


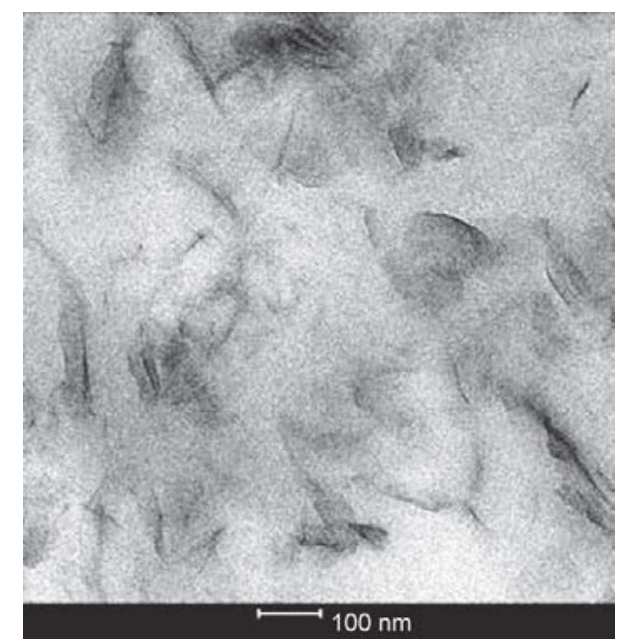

Figure 5. TEM micrograph recorded on a PA/OMMT composite containing $3 \mathrm{vol} \%$ silicate. Individual silicate layers, tactoids and the possibility of network formation.

pattern is characteristic for silicate stacks (layer distance, regularity), while the second is just an overtone, thus we do not discuss it further. The comparison of the XRD patterns to that of the neat OMMT indicates some shift in the position of the silicate reflection the extent of which is the largest in PA and much smaller in the other three polymers. Quite surprisingly the regularity in the stacking of the platelets increased considerably during homogenization in PLA, the peak became much sharper and overtones more intensive. The reason for the larger order is unclear and needs further investigation.

Although the appearance of the silicate reflection in the XRD patterns proves the presence of tactoids and particles, it does not tell anything about their amount. In order to obtain a more quantitative estimate, the

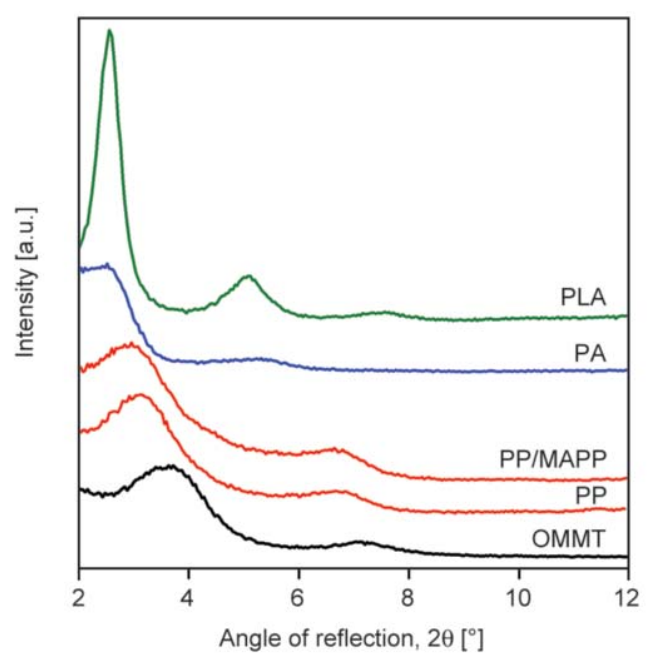

Figure 6. XRD traces of polymer/OMMT composites containing 5 vol\% silicate

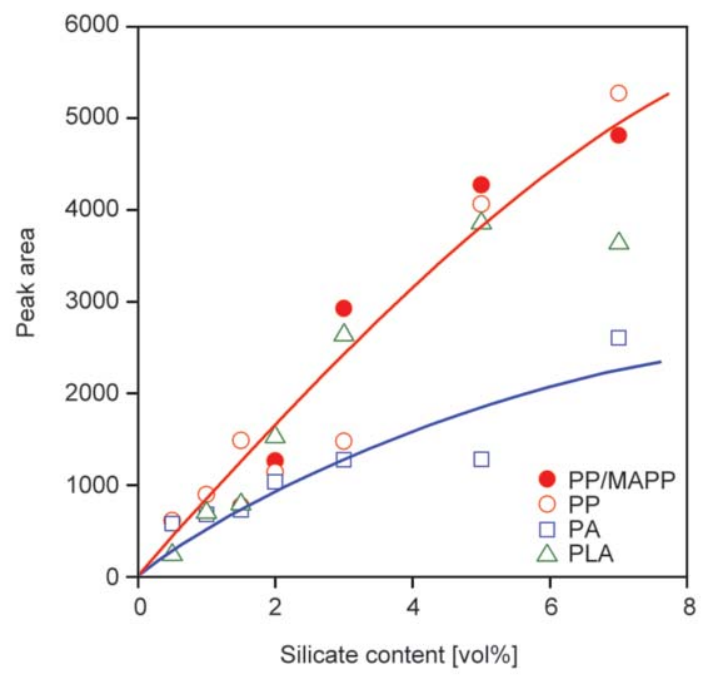

Figure 7. Correlation between the peak area of the silicate reflection and the OMMT content of the composites. Symbols are the same as in Figure 1.

silicate peaks were integrated [24]. Integration was done in the Origin 8.5 software. A baseline was fitted to the XRD traces taking into account the change in background noise with decreasing $2 \theta$ degree. Then a Lorentzian function was fitted to the peak and the area under it was integrated. The peak area obtained is plotted against silicate content in Figure 7. Although intensity is influenced by a number of factors like orientation and regularity, the quantitative comparison of the intensity of the silicate reflection indicates that the extent of exfoliation, or structural changes at least, is the largest in PA and very similar in the other three composites. The small effect of MAPP is somewhat surprising since earlier results indicated that the coupling agent assists exfoliation indeed [24].

The presence of larger particles is rarely checked in layered silicate composites, although it may influence local deformation processes and ultimately the overall properties of the composites considerably. As the SEM micrographs presented in Figure 8 show, smaller or larger particles are present in all composites. The composites were deformed up to twice their yield strain, $2 \varepsilon_{y}$, before recording the micrographs. Besides proving the presence of the particles, the micrographs offer additional information as well. The fracture of a large particle occurred in PP as shown by Figure $8 \mathrm{a}$. The size of the particle occupying the center of Figure $8 b$ is smaller and the orientation of smaller entities around it indicate that the addition of MAPP changes structure indeed. Finally apart from the one large particle seen in Figure 8c, the 


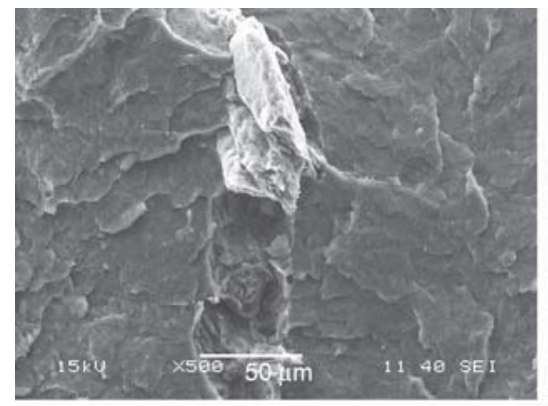

a)

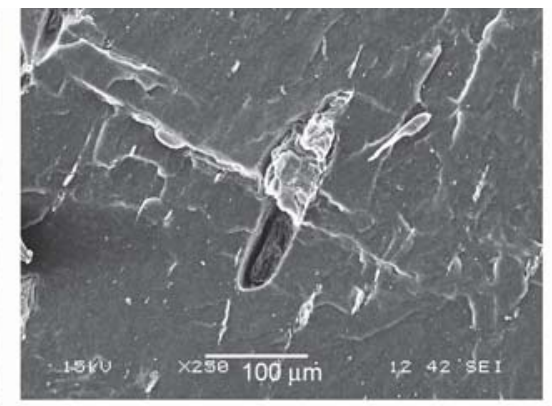

b)

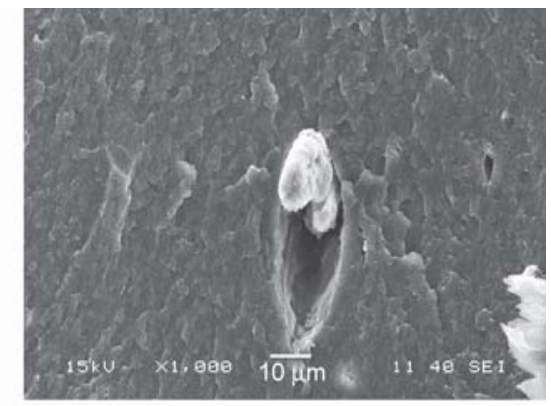

c)

Figure 8. SEM micrographs showing large particles in polymer/OMMT composites. Silicate content: a) and c) 2 vol\%, b) $3 \mathrm{vol} \%$. Specimens were deformed to $2 \varepsilon_{\mathrm{y}}$ before fracturing and recording the micrographs.

structure of the PA composite seems to be quite homogeneous. The two micrographs presented in Figures $8 \mathrm{~b}$ and $8 \mathrm{c}$ indicate that besides particle fracture, the debonding of larger particles also takes place during deformation, i.e. particle related local deformation processes occur which must influence the properties of the composites.

\subsection{Local processes}

Because of their heterogeneous structure stress distribution is inhomogeneous in composites, thus local deformations occur which depend on the elastic properties of the components, on structure and interactions. These local processes were shown to determine the final properties of composites before [50]. The micrographs presented in Figure 8 prove that local processes take place also in the layered silicate composites discussed here. Some local processes can be followed well by acoustic emission testing. Burst like processes, like particle fracture or debonding, generate elastic waves which can be detected by piezoelectric sensors. The result of such a test is shown in Figure 9. Small circles indicate individual events (signals, hits) which were recorded during a tensile test. The signals appear above a certain deformation threshold and most of the events occur in a limited range of deformation. The stress vs. strain trace is also plotted in the figure as reference. Although the distribution of signals supplies valuable information about the local process initiating it, it is difficult to evaluate them, thus the cumulative number of signals is also plotted in the figure. This confirms that most of the signals are evolved above a threshold deformation and stress, and that the trace goes to saturation. Usually such traces are obtained when debonding or particle fracture is the dominating local deformation processes. Plotting the cumulative number of signals against deformation allows the determination

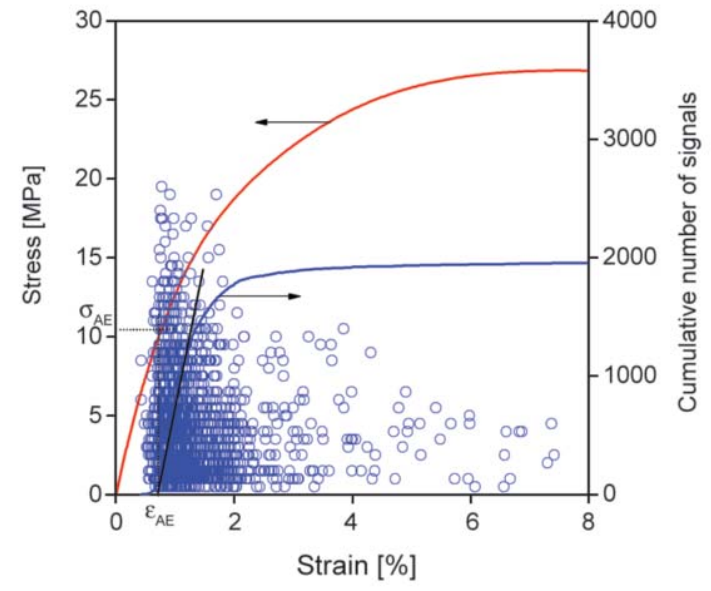

Figure 9. Acoustic emission testing of a PP/OMMT composite. Silicate content: 5 vol\%. (०) individual acoustic events. Continuous lines are stress vs. strain traces plotted as reference (left axis, red line) and the cumulative number of signals vs. strain correlation (right axis, blue line).

of a characteristic deformation $\left(\varepsilon_{\mathrm{AE}}\right)$ and stress $\left(\sigma_{\mathrm{AE}}\right)$ value as shown in Figure 9.

The cumulative number of signal traces are compared to each other in Figure 10 for the four composites all of them containing $5 \mathrm{vol} \%$ silicate. The traces are very similar, but the number of detected signals differs considerably. A relatively large number of signals are detected in PP and PLA, although this latter fails at small deformation because the large stiffness of the matrix is further enhanced by the presence of the silicate. MAPP changes structure and interfacial adhesion. Smaller particles do not fracture and debonding is more difficult at stronger interfacial adhesion, thus less signals are detected. We assume that the debonding of a few particles yield acoustic events in PA, in accordance with the largest reinforcement and most homogeneous structure of the composite prepared from this polymer.

Some of the local processes occurring during the deformation of composites, like debonding and 


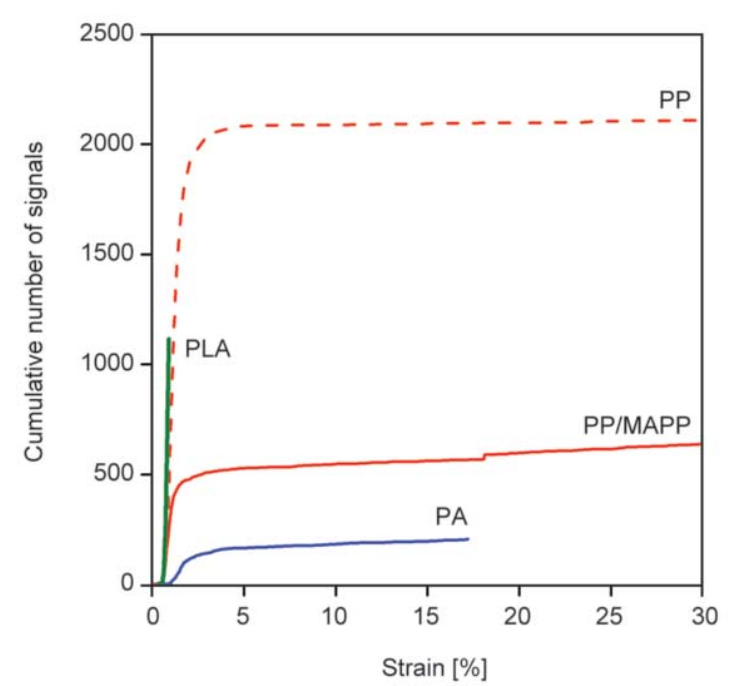

Figure 10. Comparison of the cumulative number of signal vs. strain traces for composites prepared with various matrix polymers. Silicate content: 5 vol\%.

cavitation, are accompanied by volume increase which can be followed by the measurement of volume strain. Other processes, like particle fracture or the shear yielding of the matrix occur at constant volume. The volume strain measured during the deformation of a PLA composite is presented in Figure 11 together with that of the neat matrix polymer as comparison. The initial increase of volume is caused by the Poisson's ratio of the polymer being different from 0.5 , but the steeper increase above $2.5 \%$ linear elongation is the result of a local process. Several processes may initiate volume increase, as mentioned above, among others debonding, crazing and

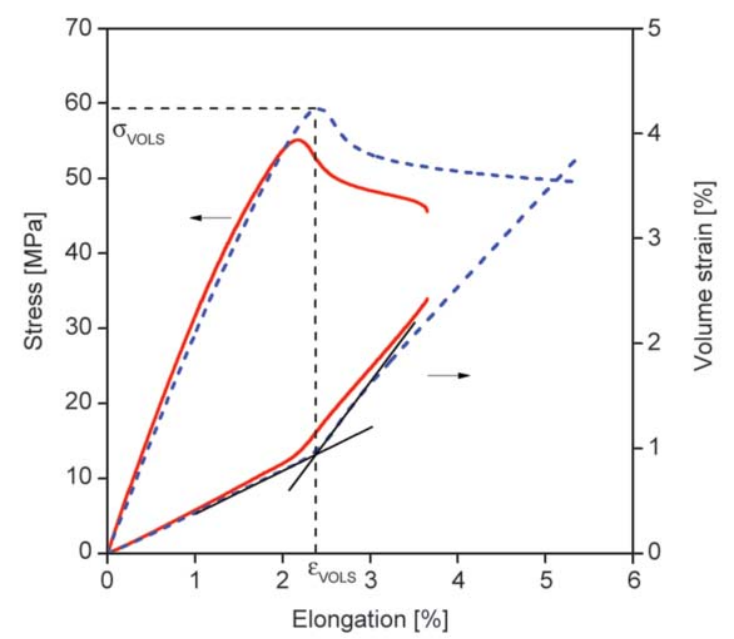

Figure 11. Volume strain of a PLA/OMMT composite. Silicate content is $2 \mathrm{vol} \%$ ( - ). The correlation obtained for the matrix polymer (-----) is shown for comparison. The corresponding stress vs. strain traces are also plotted as reference.

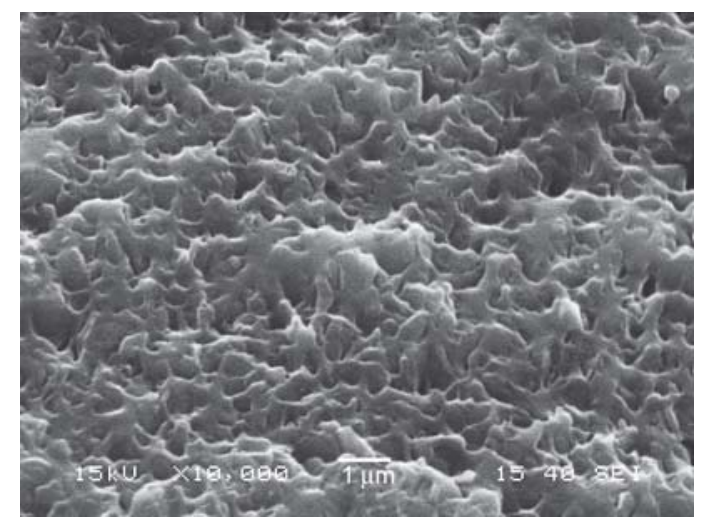

Figure 12. SEM micrograph taken from the fracture surface of a PLA/OMMT composite containing 2 vol\% silicate. Extensive cavitation of the matrix.

cavitation. Since SEM micrographs showed debonding in most composites, it would be the obvious selection as the source of volume increase. However, a detailed microscopic study showed considerable cavitation of the matrix both in PLA (see Figure 12) and in PA composites thus it may contribute or even dominate volume increase. Unfortunately, volume increase could not be measured in PP composites since the mechanical strain gauge used initiated the macroscopic yielding of the specimens. Nevertheless, we can conclude that a number of local processes take place during the deformation of our composites, which may determine their macroscopic properties.

\subsection{Interactions}

The results presented above clearly show that the structure of the composites is different and these differences are reflected in their properties. Since the chemical structure of the four matrices differs considerably from each other we may safely assume that also their interaction with the silicate is dissimilar. The degree of exfoliation is determined by thermodynamic and kinetic factors, thus surface properties and interactions must be analyzed to explain structural differences. Parameters related to interactions are listed in Table 2 . The surface tension of the polymers appears in column one. The smallest surface tension was measured for PP, as expected. The surface tension of the other two polymers is larger because of the polar groups in their structures and we may assume that PA can form the strongest interactions. The surface tension of MAPP was measured as $34.5 \mathrm{~mJ} / \mathrm{m}^{2}$, but because of its reactivity, it may develop even chemical bonds with some of the components of the composite [51]. We must pay special attention to the surface tension of the organophilic 
Table 2. Quantities related to interfacial adhesion in polymer/OMMT nanocomposites determined by various approaches

\begin{tabular}{|l|c|c|c|c|}
\hline Component & $\begin{array}{c}\boldsymbol{\gamma}_{\mathbf{s}}{ }^{\mathbf{2}} \\
{\left[\mathbf{m} \mathbf{J} / \mathbf{m}^{2}\right]}\end{array}$ & $\begin{array}{c}\boldsymbol{W}_{\mathbf{A B}} \\
{\left[\mathbf{m J} / \mathbf{m}^{2}\right]}\end{array}$ & $\begin{array}{c}\boldsymbol{F}_{\mathbf{a}} \\
{\left[\mathbf{m J} / \mathbf{m}^{2}\right]}\end{array}$ & $\boldsymbol{B}_{\mathbf{y}}$ \\
\hline PP & 33.7 & 76.4 & $158 \pm 40$ & 1.5 \\
\hline PP/MAPP & - & - & $198 \pm 32$ & 3.5 \\
\hline PLA & 43.5 & 95.0 & $292 \pm 49$ & 1.2 \\
\hline PA & 46.5 & 108.6 & $357 \pm 298$ & 4.5 \\
\hline
\end{tabular}

${ }^{a}$ The surface tension of OMMT is $66.3 \mathrm{~mJ} / \mathrm{m}^{2}$ and that of MAPP is $34.5 \mathrm{~mJ} / \mathrm{m}^{2}$

montmorillonite. The non-treated silicate has a very high surface energy [33] $\left(\sim 780 \mathrm{~mJ} / \mathrm{m}^{2}\right)$, but organophilization decreases it to the same level as the polymers used in this study. Decreased surface energy has the benefit of weaker adhesion among the silicate layers facilitating exfoliation, but also weaker interaction with the matrix polymer. The balance of these competitive interactions, which are of the same order of magnitude, determines the extent of exfoliation. The results also indicate that the interaction among the silicate layers is still stronger than matrix/filler interactions shown by the comparison of $W_{\mathrm{AB}}=132.6 \mathrm{~mJ} / \mathrm{m}^{2}$ for the silicate layers compared to that of the PA/ OMMT composite which is $108.6 \mathrm{~mJ} / \mathrm{m}^{2}$.

The direct determination of the strength of matrix/ filler adhesion is difficult, if not impossible, thus we can only estimate it with various indirect methods. The easiest is the calculation of the reversible work of adhesion $\left(W_{\mathrm{AB}}\right)$ from the surface tension of the components as shown in Equation (1):

$W_{\mathrm{AB}}=2\left(\gamma_{1}^{\mathrm{d}} \gamma_{2}^{\mathrm{d}}\right)^{1 / 2}+2\left(\gamma_{1}^{\mathrm{p}} \gamma_{2}^{\mathrm{p}}\right)^{1 / 2}$

where $p$ and $d$ stands for the dispersion and polar components of the surface tension $(\gamma)$ of components 1 and 2, respectively. Work of adhesions reflect the relations shown by surface tensions; the strongest matrix/silicate interaction forms in PA and the weakest in PP. The relatively strong interaction predicted for PLA is somewhat surprising, especially if we consider the results of mechanical testing shown in Figures 1 and 2 .

The reversible work of adhesion approach is relatively simple. However, it ignores specific interactions and the determination of surface tensions is not very easy either. Further information can be obtained about interactions from acoustic emission experiments. If debonding is the dominating deformation mechanism, the separation of the matrix/filler interface depends on several factors including interfacial adhesion; see Equation (2)

$\sigma^{\mathrm{D}}=-C_{1} \sigma^{\mathrm{T}}+C_{2}\left(\frac{E F_{\mathrm{a}}}{R}\right)^{1 / 2}$

where $\sigma^{\mathrm{D}}$ and $\sigma^{\mathrm{T}}$ are debonding and thermal stresses, respectively, $E$ the Young's modulus of the matrix, $R$ the radius of the particles and $F_{\mathrm{a}}$ interfacial adhesion. $C_{1}$ and $C_{2}$ are geometric constants related to the debonding process. If we know them, we can calculate $F_{\mathrm{a}}$, since the rest of the variables are usually known [40]. The values calculated from characteristic stress values determined by acoustic emission are listed in column four of Table 2 . The results confirm the previously established order, the strongest interaction develops in PA and the weakest in PP. The relatively large value obtained for PLA is somewhat surprising as well as the smaller value obtained for the PP/MAPP matrix. The drawback of the approach is that the fracture of particles also gives acoustic signals and this may bias the evaluation of the results. On the other hand, we may assume that debonding also occurs as shown in Figures $8 \mathrm{~b}$ and $8 \mathrm{c}$ and that smaller particles do not break, but debond thus the values presented in Table 2 give some indication about interfacial adhesion.

If debonding is the main local deformation process, the strength of interaction can be estimated also from the composition dependence of tensile yield stress by an appropriate model given by Equation (3):

$\sigma_{\mathrm{y}}=\sigma_{\mathrm{y} 0} \frac{1-\varphi}{1+2.5 \varphi} \exp (B \varphi)$

where $\sigma_{\mathrm{y}}$ and $\sigma_{\mathrm{y} 0}$ are the tensile yield stress of the composite and the matrix, respectively, $\varphi$ is the volume fraction of the silicate and $B$ is related to its relative load-bearing capacity, i.e. to the extent of reinforcement, which depends among other factors also on interfacial interaction. $B$ parameters determined from the tensile yield stress of the composites are listed in column five of Table 2 . The results show that the strongest interactions develop in PA and the weakest in PLA in this case. The values obtained for the other two matrices are in between, but deviate somewhat from the other two predictions. We must be aware of the fact that two factors determine the value of $B$, the extent of exfoliation through the contact surface between the silicate and the polymer and interfacial interaction $[37,38]$. Moreover, $B$ is influenced also by the corresponding property of the matrix, smaller 
values are obtained in stiffer and stronger matrices. In spite of the difficulties in evaluation and in taking into account all factors, the message of the results is clear: interactions are competitive, they are different in the various polymers and determine structure as well as properties.

\subsection{Discussion, correlations}

The properties of the composites are determined by their structure and this latter is mainly controlled by competitive interactions. Several local deformation processes occur during the deformation of the composites both in the matrix and around larger entities of the silicate (stacks, particles). The ultimate properties of the composites are determined by the combined effect of these factors. The relationship of various processes can be seen reasonably well if we compare the composition dependence of characteristic stresses as shown by Figure 13 for PA. The increase of volume is initiated at relatively small stresses. The related process was identified earlier as cavitation [52]. Particle fracture and/or debonding starts at slightly larger stress as shown by the characteristic stress determined by the acoustic emission measurement. Tensile yield stress and strength are much larger indicating that local processes do not influence these later. Interactions determine the extent of exfoliation, but composite properties are dominated mainly by matrix characteristics and not by interactions or structure.

The role of local processes as well as interactions is completely different in PLA (Figure 14). Acoustic

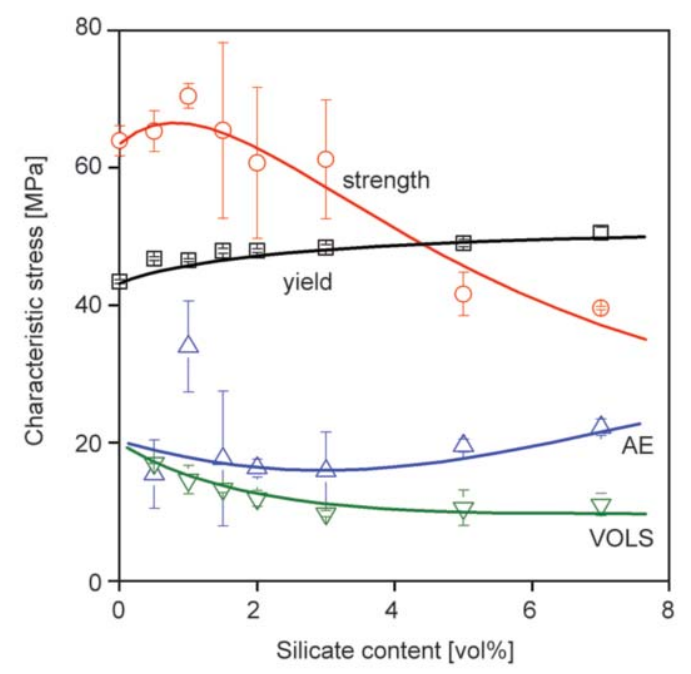

Figure 13. Dependence of the characteristic stresses of PA/ OMMT composites on silicate content. Symbols: $(\nabla)$ VOLS, volume strain, $(\triangle) \mathrm{AE}$, acoustic emission, $(\square)$ yield stress, $(\circ)$ tensile strength.

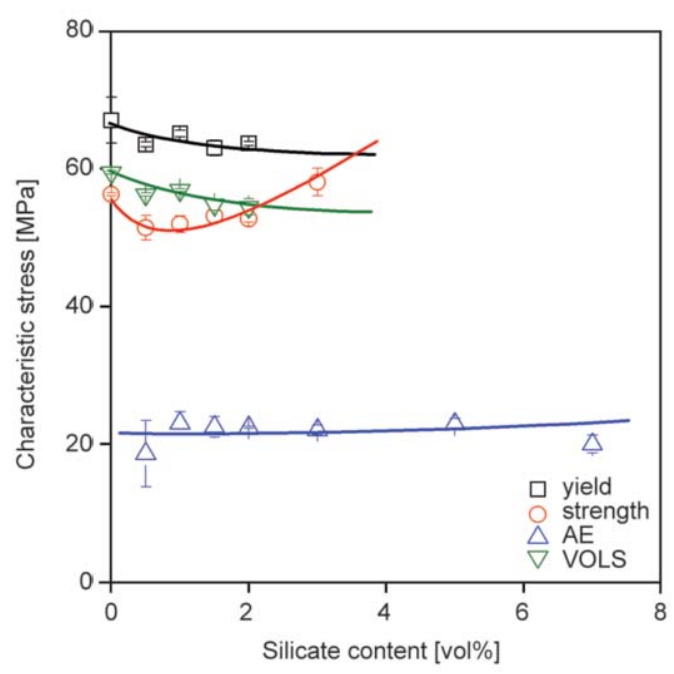

Figure 14. Characteristic stress values of PLA/OMMT composites plotted against silicate content. Symbols are the same as in Figure 13.

emission events are initiated at small stresses and because of weak interactions it can be mainly debonding and some particle fracture. Volume strain initiates yielding and this latter is close to the fracture of the polymer. Particle related processes are not very important in this polymer either. Although volume strain could not be measured in PP the relationship of the rest of the characteristic quantities indicate that particle related processes are much more important in this polymer both at poor and good adhesion, i.e. with and without the MAPP coupling agent. This statement is especially valid for neat PP, since improved adhesion results in very small deformations (see Figure 3) and premature failure.

The analysis of local processes showed that all composites have some acoustic activity and according to Figure 10 it is different in the various matrices. We assumed that these processes are related to the number of non-exfoliated structural entities, mainly to relatively large particles. This assumption is strongly corroborated by Figure 15 showing the correlation of XRD intensity of the silicate peak and the number of acoustic signals detected up to the yielding of the specimen. The correlations are relatively close in all cases and the differences among the polymers are obvious. Although acoustic activity depends on a number of factors, it is clear that large particles are present in all of the composites and they initiate local deformation processes. Depending on the characteristics of the matrix, these processes may lead to the failure of the composite (PP).

The strength of interactions is crucial for exfoliation, but it influences local processes as well. PLA proved 


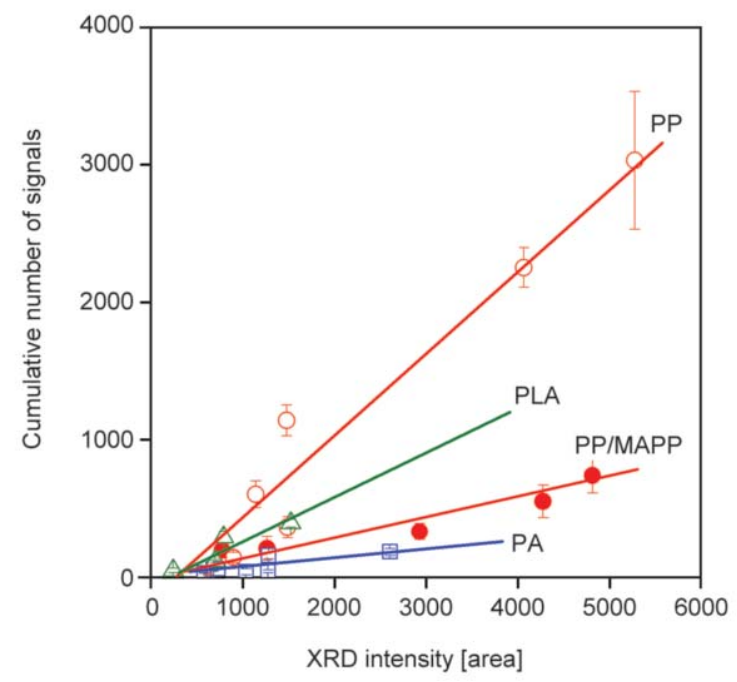

Figure 15. Correlation between the cumulative number of acoustic signals and the area under the silicate peak in the XRD pattern of polymer/OMMT composites. Symbols are the same as in Figure 1.

to be contradictory in many respects. Relatively strong interactions were estimated by two methods, while yield stress and parameters derived from it contradicted this. We mentioned that parameter $\mathrm{B}$ depends on the extent of exfoliation, but also on the characteristics of the matrix. The relationship between this parameter and matrix yield stress is plotted against each other in Figure 16 for a series of polymer/zeolite composites as reference. The results obtained for the investigated four sets of composites are also plotted in the figure. Most of the points fit the general tendency quite well, only the PA composite deviates more significantly, its performance is better than the

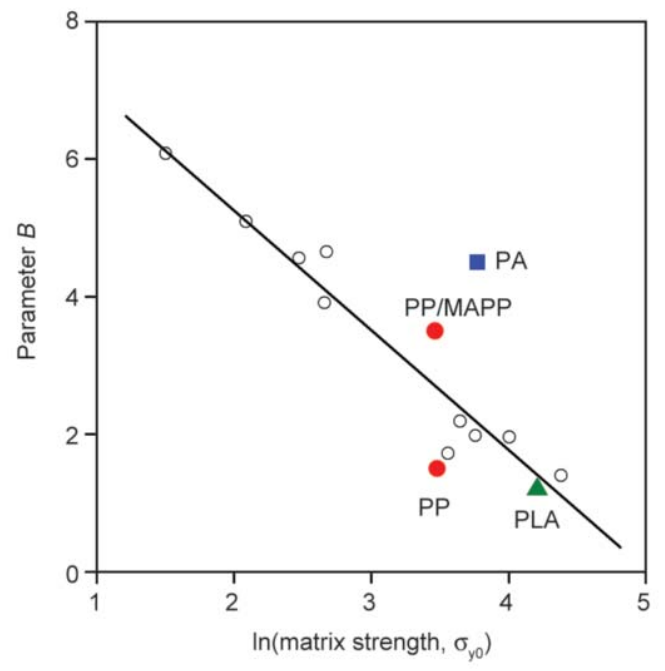

Figure 16. Dependence of the load bearing capacity of the silicate (parameter $B_{\mathrm{y}}$ ) on the yield stress of the matrix; ( $\circ$ ) polymer/zeolite composites used as reference average. This deviation certainly results from larger extent of exfoliation and stronger interactions. PLA fits the general line thus the larger adhesion estimated from AE measurements is definitely caused by the larger strength of this matrix. Although the structure of the polymer/silicate composites studied in this work is complex and the relationships among interactions, structure and properties are complicated we can clearly establish the role of competitive interactions in the determination of the extent of exfoliation and macroscopic properties.

\section{Conclusions}

The comparison of polymer/OMMT composites prepared with four matrices of different chemical structure showed that competitive interactions among silicate layers and between the silicate and the polymer determine the extent of exfoliation and structure generally. The morphology of the composites is complicated, various structural entities can be present in them. Exfoliation is never complete, besides individual silicate layers, the composite can contain a silicate network, stacks of silicate plates and larger particles in various amounts. Several local deformation processes can take place around these structural entities as well as in the matrix. The dominating process depends on interactions, and on the size and amount of the heterogeneities. The main particle related processes are particle fracture and debonding, while cavitation takes place in the polymer, at least in PA and PLA matrices. The macroscopic properties of layered silicate composites are determined by the balance of the extent of exfoliation and interfacial adhesion that decreases upon organophilization. Increased reinforcement and improved composite properties can be achieved only by the proper control of all interactions prevailing in the composite.

\section{Acknowledgements}

The authors are indebted to Balázs Tar and Gábor Lipták for sample preparation and the evaluation of the results, to Nóra Hegyesi for the rheological analysis, to István Sajó for his assistance in the WAXS measurements, and to Elodie Naveau and the 'Cellule d'Appui Technologique en Microscopie' (CAT $\mu, \mathrm{ULg}$ ), Université de Liège for collecting the TEM images. The authors acknowledge the financial support of the National Scientific Research Fund of Hungary (OTKA Grant No. K 120039 and PD 112489) for this project on the structureproperty correlations of polymeric materials. The research work has been part of the BME R+D+I project supported by the grant TÁMOP 4.2.1/B-09/1/KMR-2010-0002. 


\section{References}

[1] de Leon A. C., Chen Q., Palaganas N. B., Palaganas J. O., Manapat J., Advincula R. C.: High performance polymer nanocomposites for additive manufacturing applications. Reactive and Functional Polymers, 103, 141155 (2016).

https://doi.org/10.1016/j.reactfunctpolym.2016.04.010

[2] Khobragade P. S., Hansora D. P., Naik J. B., Chatterjee A.: Flame retarding performance of elastomeric nanocomposites: A review. Polymer Degradation and Stability, 130, 194-244 (2016).

https://doi.org/10.1016/j.polymdegradstab.2016.06.001

[3] Kim D. J., Jo M. J., Nam S. Y.: A review of polymernanocomposite electrolyte membranes for fuel cell application. Journal of Industrial and Engineering Chemistry, 21, 36-52 (2015).

https://doi.org/10.1016/j.jiec.2014.04.030

[4] Kotal M., Bhowmick A. K.: Polymer nanocomposites from modified clays: Recent advances and challenges. Progress in Polymer Science, 51, 127-187 (2015).

https://doi.org/10.1016/j.progpolymsci.2015.10.001

[5] Pavlidou S., Papaspyrides C. D.: A review on polymerlayered silicate nanocomposites. Progress in Polymer Science, 33, 1119-1198 (2008).

https://doi.org/10.1016/j.progpolymsci.2008.07.008

[6] Tan B., Thomas N. L.: A review of the water barrier properties of polymer/clay and polymer/graphene nanocomposites. Journal of Membrane Science, 514, 595612 (2016).

https://doi.org/10.1016/j.memsci.2016.05.026

[7] Abt T., Bou J. J., Sánchez-Soto M.: Isocyanate toughening of pCBT/organoclay nanocomposites with exfoliated structure and enhanced mechanical properties. Express Polymer Letters, 8, 953-966 (2014). https://doi.org/10.3144/expresspolymlett.2014.96

[8] Ramoa S. D. A. S., Barra G. M. O., Merlini C., Livi S., Soares B. G., Pegoretti A.: Novel electrically conductive polyurethane/montmorillonite-polypyrrole nanocomposites. Express Polymer Letters, 9, 945-958 (2015). https://doi.org/10.3144/expresspolymlett.2015.85

[9] Rusmirović J. D., Trifković K. T., Bugarski B., Pavlović V. B., Džunuzović J., Tomić M., Marinković A. D.: High performance unsaturated polyester based nanocomposites: Effect of vinyl modified nanosilica on mechanical properties. Express Polymer Letters, 10, 139-159 (2016). https://doi.org/10.3144/expresspolymlett.2016.14

[10] Haider S., Kausar A., Muhammad B.: Overview of various sorts of polymer nanocomposite reinforced with layered silicate. Polymer-Plastics Technology and Engineering, 55, 723-743 (2016). https://doi.org/10.1080/03602559.2015.1098701

[11] Gul S., Kausar A., Muhammad B., Jabeen S.: Research progress on properties and applications of polymer/clay nanocomposite. Polymer-Plastics Technology and Engineering, 55, 684-703 (2016).

https://doi.org/10.1080/03602559.2015.1098699
[12] Jagtap S. B., Mohan M. S., Shukla P. G.: Improved performance of microcapsules with polymer nanocomposite wall: Preparation and characterization. Polymer, 83, 27-33 (2016).

https://doi.org/10.1016/j.polymer.2015.12.011

[13] Momani B., Sen M., Endoh M., Wang X., Koga T., Winter H.: Temperature dependent intercalation and self-exfoliation of clay/polymer nanocomposite. Polymer, 93, 204-212 (2016).

https://doi.org/10.1016/j.polymer.2016.03.010

[14] Xiao S., Peter C., Kremer K.: Systematic comparison of model polymer nanocomposite mechanics. Bioinspiration \& Biomimetics, 11, 055008/1--055008/14 (2016). https://doi.org/10.1088/1748-3190/11/5/055008

[15] Alexandre M., Dubois P.: Polymer-layered silicate nanocomposites: Preparation, properties and uses of a new class of materials. Materials Science and Engineering R: Reports, 28, 1-63 (2000).

https://doi.org/10.1016/S0927-796X(00)00012-7

[16] Sinha Ray S., Okamoto M.: Polymer/layered silicate nanocomposites: A review from preparation to processing. Progress in Polymer Science, 28, 1539-1641 (2003). https://doi.org/10.1016/j.progpolymsci.2003.08.002

[17] Okada A., Usuki A.: The chemistry of polymer-clay hybrids. Materials Science and Engineering: C, 3, 109-115 (1995).

https://doi.org/10.1016/0928-4931(95)00110-7

[18] Kojima Y., Usuki A., Kawasumi M., Okada A., Fukushima Y., Kurauchi T., Kamigaito O.: Mechanical properties of nylon 6-clay hybrid. Journal of Materials Research, 8, 1185-1189 (1993).

https://doi.org/10.1557/jmr.1993.1185

[19] Kaempfer D., Thomann R., Mülhaupt R.: Melt compounding of syndiotactic polypropylene nanocomposites containing organophilic layered silicates and in situ formed core/shell nanoparticles. Polymer, 43, 29092916 (2002).

https://doi.org/10.1016/s0032-3861(02)00113-1

[20] Reichert P., Hoffmann B., Bock T., Thomann R., Mülhaupt R., Friedrich C.: Morphological stability of poly (propylene) nanocomposites. Macromolecular Rapid Communications, 22, 519-523 (2001).

https://doi.org/10.1002/1521-3927(20010401)22:7<519::aidmarc519>3.3.co; $2-n$

[21] Hasegawa N., Usuki A.: Silicate layer exfoliation in polyolefin/clay nanocomposites based on maleic anhydride modified polyolefins and organophilic clay. Journal of Applied Polymer Science, 93, 464-470 (2004). https://doi.org/10.1002/app.20459

[22] Shiravand F., Hutchinson J. M., Calventus Y.: A novel comparative study of different layered silicate clay types on exfoliation process and final nanostructure of trifunctional epoxy nanocomposites. Polymer Testing, 56, 148-155 (2016). https://doi.org/10.1016/j.polymertesting.2016.10.007 
[23] Chin I-J., Thurn-Albrecht T., Kim H-C., Russell T. P., Wang J.: On exfoliation of montmorillonite in epoxy. Polymer, 42, 5947-5952 (2001). https://doi.org/10.1016/S0032-3861(00)00898-3

[24] Százdi L., Ábrányi Á., Pukánszky B. Jr., Vancso J. G., Pukánszky B.: Morphology characterization of PP/clay nanocomposites across the length scales of the structural architecture. Macromolecular Materials and Engineering, 291, 858-868 (2006).

https://doi.org/10.1002/mame.200600026

[25] Zhao J., Morgan A. B., Harris J. D.: Rheological characterization of polystyrene-clay nanocomposites to compare the degree of exfoliation and dispersion. Polymer, 46, 8641-8660 (2005).

https://doi.org/10.1016/j.polymer.2005.04.038

[26] Durmus A., Kasgoz A., Macosko C. W.: Linear low density polyethylene (LLDPE)/clay nanocomposites. Part I: Structural characterization and quantifying clay dispersion by melt rheology. Polymer, 48, 4492-4502 (2007).

https://doi.org/10.1016/j.polymer.2007.05.074

[27] As'habi L., Jafari S. H., Khonakdar H. A., Boldt R., Wagenknecht U., Heinrich G.: Tuning the processability, morphology and biodegradability of clay incorporated PLA/LLDPE blends via selective localization of nanoclay induced by melt mixing sequence. Express Polymer Letters, 7, 21-39 (2013).

https://doi.org/10.3144/expresspolymlett.2013.3

[28] Malkappa K., Rao B. N., Jana T.: Functionalized polybutadiene diol based hydrophobic, water dispersible polyurethane nanocomposites: Role of organo-clay structure. Polymer, 99, 404-416 (2016).

https://doi.org/10.1016/j.polymer.2016.07.039

[29] Sownthari K., Suthanthiraraj S. A.: Preparation and properties of biodegradable polymer-layered silicate nanocomposite electrolytes for zinc based batteries. Electrochimica Acta, 174, 885-892 (2015).

https://doi.org/10.1016/j.electacta.2015.06.049

[30] Tamura K., Ohyama S., Umeyama K., Kitazawa T., Yamagishi A.: Preparation and properties of halogen-free flame-retardant layered silicate-polyamide 66 nanocomposites. Applied Clay Science, 126, 107-112 (2016). https://doi.org/10.1016/j.clay.2016.02.027

[31] Dennis H. R., Hunter D. L., Chang D., Kim S., White J. L., Cho J. W., Paul D. R.: Effect of melt processing conditions on the extent of exfoliation in organoclaybased nanocomposites. Polymer, 42, 9513-9522 (2001). https://doi.org/10.1016/S0032-3861(01)00473-6

[32] LeBaron P. C., Wang Z., Pinnavaia T. J.: Polymer-layered silicate nanocomposites: An overview. Applied Clay Science, 15, 11-29 (1999). https://doi.org/10.1016/S0169-1317(99)00017-4

[33] Kádár F., Százdi L., Fekete E., Pukánszky B.: Surface characteristics of layered silicates: Influence on the properties of clay/polymer nanocomposites. Langmuir, 22, 7848-7854 (2006).

https://doi.org/10.1021/la060144c
[34] Mesbah A., Zaïri F., Naït-Abdelaziz M., Gloaguen J. M., Anoukou K., Zaoui A., Qu Z., Boukharouba T., Lefebvre J. M.: Micromechanics-based constitutive modeling of plastic yielding and damage mechanisms in polymer-clay nanocomposites: Application to polyamide- 6 and polypropylene-based nanocomposites. Composites Science and Technology, 101, 71-78 (2014). https://doi.org/10.1016/j.compscitech.2014.05.032

[35] Stoeffler K., Lafleur P. G., Perrin-Sarazin F., Bureau M. N., Denault J.: Micro-mechanisms of deformation in polyethylene/clay micro- and nanocomposites. Composites Part A: Applied Science and Manufacturing, 42, 916-927 (2011).

https://doi.org/10.1016/j.compositesa.2011.03.020

[36] Dominkovics Z., Hári J., Fekete E., Pukánszky B.: Thermo-oxidative stability of polypropylene/layered silicate nanocomposites. Polymer Degradation and Stability, 96, 581-587 (2011).

https://doi.org/10.1016/j.polymdegradstab.2010.12.012

[37] Pukánszky B.: Influence of interface interaction on the ultimate tensile properties of polymer composites. Composites, 21, 255-262 (1990). https://doi.org/10.1016/0010-4361(90)90240-w

[38] Pukánszky B., Turcsányi B., Tüdős F: Effect of interfacial interaction on the tensile yield stress of polymer composites. Elsevier, New York (1988).

[39] Pukánszky B., Vörös G.: Mechanism of interfacial interactions in particulate filled composites. Composite Interfaces, 1, 411-427 (1993). https://doi.org/10.1163/156855493X00266

[40] Renner K., Móczó J., Vörös G., Pukánszky B.: Quantitative determination of interfacial adhesion in composites with strong bonding. European Polymer Journal, 46, 2000-2004 (2010). https://doi.org/10.1016/j.eurpolymj.2010.07.008

[41] Fu S-Y., Lauke B., Mäder E., Yue C-Y., Hu X.: Tensile properties of short-glass-fiber- and short-carbon-fiberreinforced polypropylene composites. Composites Part A: Applied Science and Manufacturing, 31, 1117-1125 (2000).

https://doi.org/10.1016/S1359-835X(00)00068-3

[42] Nicolais L., Narkis M.: Stress-strain behavior of styreneacrylonitrile/glass bead composites in the glassy region. Polymer Engineering and Science, 11, 194-199 (1971). https://doi.org/10.1002/pen.760110305

[43] Wang Z., Pinnavaia T. J.: Hybrid organic-inorganic nanocomposites: Exfoliation of magadiite nanolayers in an elastomeric epoxy polymer. Chemistry of Materials, 10, 1820-1826 (1998). https://doi.org/10.1021/cm970784o

[44] Messersmith P. B., Giannelis E. P.: Synthesis and characterization of layered silicate-epoxy nanocomposites. Chemistry of Materials, 6, 1719-1725 (1994).

https://doi.org/10.1021/cm00046a026 
[45] Pinnavaia T. J., Lan T., Wang Z., Shi H. Z., Kaviratna P. D.: Clay-reinforced epoxy nanocomposites: Synthesis, properties, and mechanism of formation. in 'Nanotechnology: Molecularly designed materials' (eds.: Chow G. M., Gonsalves K. E.) American Chemical Society, Washington, Vol 622, 250-261 (1996).

[46] Tjong S. C.: Structural and mechanical properties of polymer nanocomposites. Materials Science and Engineering R: Reports, 53, 73-197 (2006).

https://doi.org/10.1016/j.mser.2006.06.001

[47] Carreau P. J., Bousmina M., Ajji A.: Progress in pacific polymer science. Springer, Berlin (1994).

[48] Zheng Q., Du M., Yang B., Wu G.: Relationship between dynamic rheological behavior and phase separation of poly(methyl methacrylate)/poly(styrene-coacrylonitrile) blends. Polymer, 42, 5743-5747 (2001). https://doi.org/10.1016/S0032-3861(01)00025-8

[49] Cole K. S., Cole R. H.: Dispersion and absorption in dielectrics I. Alternating current characteristics. The Journal of Chemical Physics, 9, 341-351 (1941).

https://doi.org/10.1063/1.1750906
[50] Renner K., Móczó J., Suba P., Pukánszky B.: Micromechanical deformations in PP/lignocellulosic filler composites: Effect of matrix properties. Composites Science and Technology, 70, 1141-1147 (2010). https://doi.org/10.1016/j.compscitech.2010.02.029

[51] Százdi L., Pukánszky Jr B., Földes E., Pukánszky B.: Possible mechanism of interaction among the components in MAPP modified layered silicate PP nanocomposites. Polymer, 46, 8001-8010 (2005). https://doi.org/10.1016/j.polymer.2005.06.108

[52] Dominkovics Z., Naveau E., Jérôme C., Hári J., Renner K., Móczó J., Alexandre M., Pukánszky B.: Effect of clay modification on the mechanism of local deformations in PA6 nanocomposites. Macromolecular Materials and Engineering, 298, 796-805 (2013). https://doi.org/10.1002/mame.201200244 